\title{
La cultura tradicional de la viña en la Ribera del Duero (Burgos)
}

El cultivo de la vid en esta región, que comprende además de la parte burgalesa las tierras aledañas de Soria, Segovia y Valladolid, actualmente está en franca regresión, a pesar de que no hace mucho se concedió para sus vinos la denominación de origen «Ribera del Duero».

Desde la Edad Media, prácticamente desde la repoblación hasta el siglo XIX, la viña fue el modo de vida predominante en la región y el vino el único producto con excedentes comercializables. La razón fundamental era su situación cercana a los mercados urbanos del norte, fundamentalmente Burgos, que absorbían esos excedentes; tampoco hay que olvidar unas condiciones ecológicas más favorables que las de otras regiones de Castilla la Vieja. Con la llegada del ferrocarril estos vinos de poca calidad debido a su antiquísimo y rudimentario método de elaboración, como después veremos, pierden competitividad en favor de los de regiones meridionales y sólo pueden conservar el mercado residual de las tierras serranas, aisladas de los nuevos circuitos comerciales.

A todo esto podemos añadir factores importantes como la devastadora presencia de la filoxera, que obligó a la reposición total de las plantaciones, o la mecanización producida a partir de los años sesenta de nuestro siglo, que hace mucho más rentables los cultivos cerealísticos. En esa década el método tradicional de vinificación es sustituido por las «Bodegas Cooperativas» que lo modernizan y reducen drásticamente los costes enormes en personal que el sistema tradicional tenía, en unos años en que estaba en pleno auge el éxodo rural y la mano de obra empezaba a encarecerse.

Pero en este trabajo me limitaré a recoger, precisamente, las formas y maneras de trabajar la viña y de elaborar el vino que estuvieron vigentes desde épocas medievales hasta mediados del presente siglo, según los testimonios recogidos fundamentalmente en uno de los pueblos de la región, Castrillo de la Vega. 


\section{EL TERRENO}

Los campesinos distinguen estos tipos de tierra:

- Toba, que es una tierra fuerte, compacta, de color blancuzco, muy apreciada para hacer adobes.

- Rubiero, arcillosa y pesada, de color encarnado.

- Tierra de casco o de prao, de color negruzco, se encuentra en zonas pantanosas y aluviales; tiene mucha materia orgánica y se considera la mejor.

- Arenosa, de color amarillento o pardo, es tierra muy suelta y seca.

- Cascajo, toda la que tiene guijarros. En unas zonas es gravilla menuda y en otras cantos de tamaño regular.

- Caliza, suele ser tierra arenosa o arcillo-arenosa con gran cantidad de trozos de piedra caliza. A veces aparecen corros calizos, blancuzcos, en medio del rubiero, conocidos como calveros.

Los tres primeros tipos de tierra son aptos para los cereales, mientras que los tres últimos, de peor calidad y los más abundantes, son mejores para viñedo por tratarse de tierras más calientes y secas.

También se tenía en cuenta el clima, caracterizado sobre todo por la gran cantidad de heladas que caen desde noviembre hasta mayo, por lo que se elegían tierras soleadas y altas, y se evitaban las que estaban en repozas o en lugares húmedos.

La preparación del terreno para la plantación de una viña era escasa: en algunos casos se dejaba un año en barbecho, pero en otros, después de la cosecha del verano, se daban dos vueltas con el arado de palo, para que desapareciese toda la maleza y se airease la tierra en otoño, cuando las lluvias lo permitían. Nunca se allanaba aunque fuese una ladera con mucha pendiente. Si después de barbechar crecía mucha hierba, se pasaba la zuela, es decir, la azada, lo que se conocía como esbrincar.

\section{Plantación de los palos}

Hasta principios de nuestro siglo la plantación se hacía sin el menor orden, ya que éste no era necesario por hacerse todos los trabajos a brazo; al introducirse en esa época el arado viñero (figs. 1 y 2) fue preciso alinear la tierra con sogas o rastras después de barbechada; esto se hace siempre en sentido longitudinal (las parcelas son todas rectangulares): desde el lado menor se trazan los líneos hasta el otro extremo menor, en los que se cavarán los hoyos con una distancia de dos metros entre palos; 

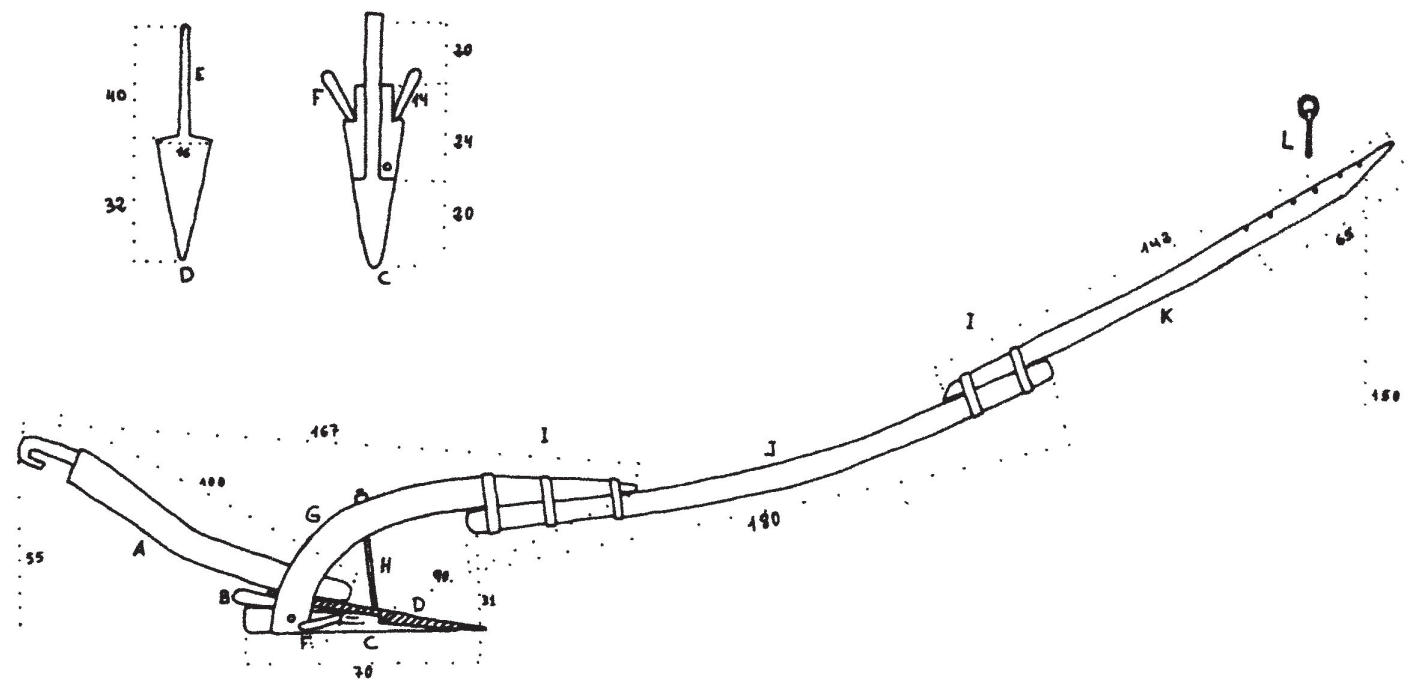

ARADO DECASTRILLO DE LAVEGA

A-esteva b-PEzcuño C-DEnTAL D-REja e-PEz Cola(delareja) f-orejeras g-cama H.CABRESTO I-BELORTAS I-TIMÓN K RASTRA L-LAVIIA

Fig. 1. Arado de Castrillo de la Vega.

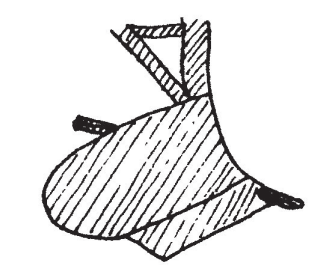

DETALLE OE LA VERTE OERA

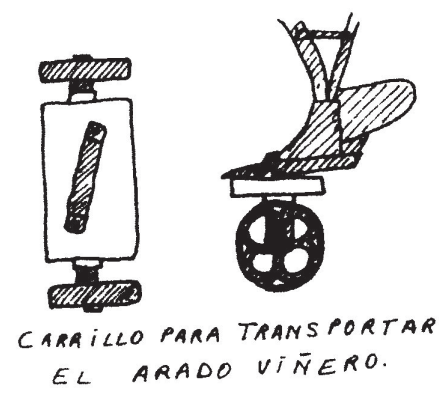

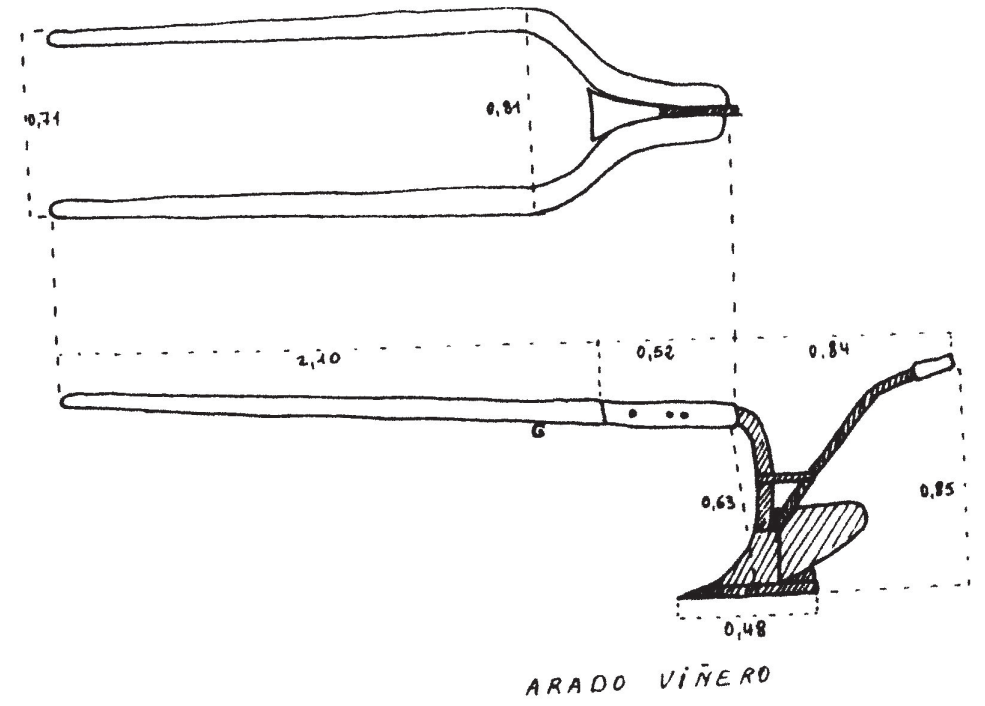

Fig. 2. Arado viñero.

el espacio que hay entre líneos se llama calle y tiene también dos metros de anchura.

Sea en total desorden, como se hacía tradicionalmente, sea alineados, como a partir de la renovación de plantas que impuso la plaga de la filoxera, los palos se plantaban: 

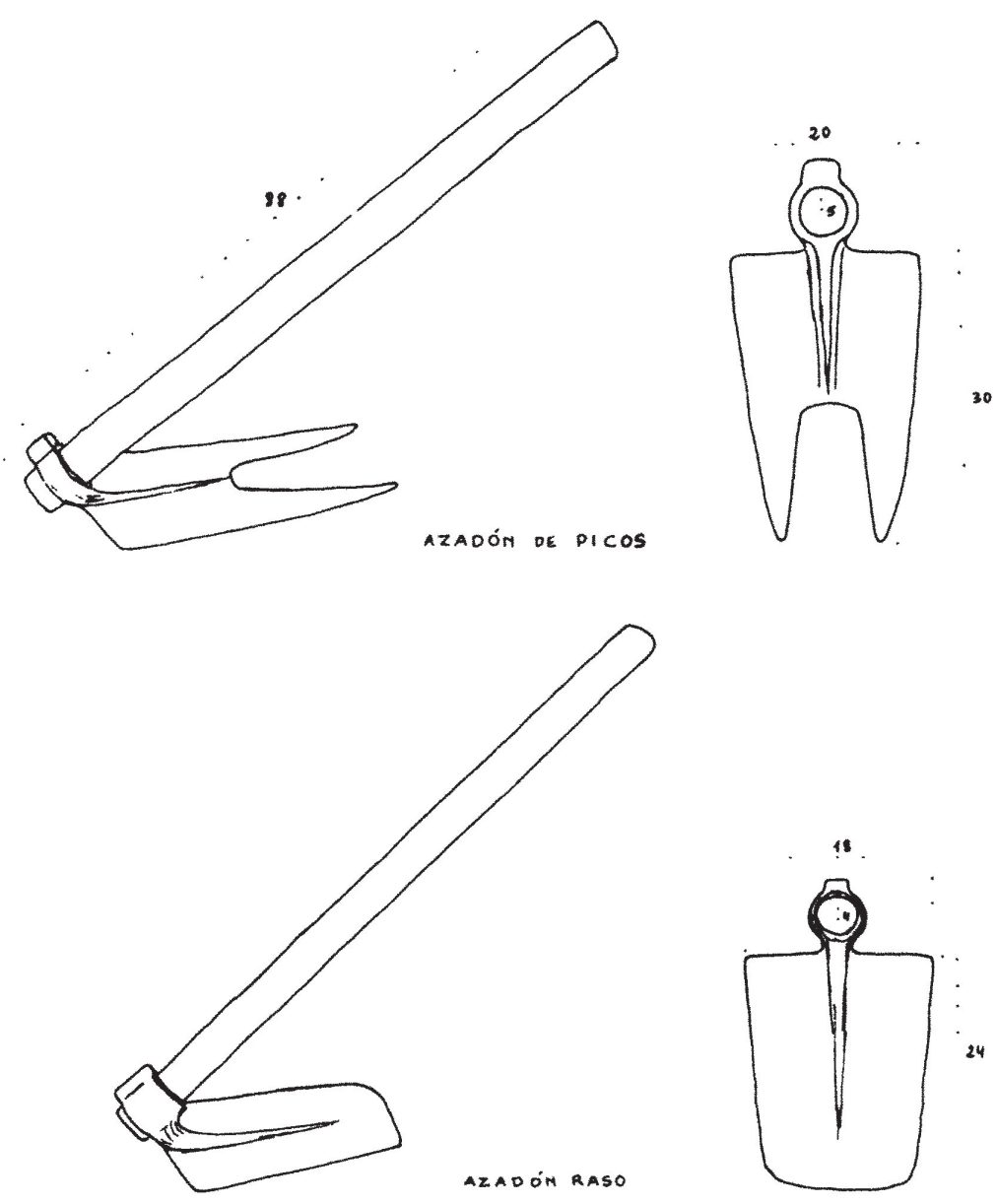

Fig. 3. Tipos de azadón.

- A boyo. Con un azadón, raso si el terreno era arenoso, o de picos si era cascajo, se hacía un hoyo de forma cuadrada de un metro de lado y unas tres cuartas $(75 \mathrm{~cm}$.) de profundidad, aproximadamente, para cada palo. Si el terreno era duro era preciso excavarlo en el montero (figs. 3 y 4 ).

- A boya. Se excivaba un hoyo mucho mayor que en el caso anterior, de forma rectangular, en el que se plantaban dos palos, uno a cada extremo.

- A barrón, o a barra. «Se ponía un plantel a barrón» cuando la tierra era especialmente dura o en los cascajos; se utilizaba una barra de hierro, maciza, de metro y medio de largo y unos cuatro centímetros de diámetro con la que se practicaba un agujero en el suelo, a fuerza de golpes, de la misma profundidad que los hoyos (ver fig. 5). 


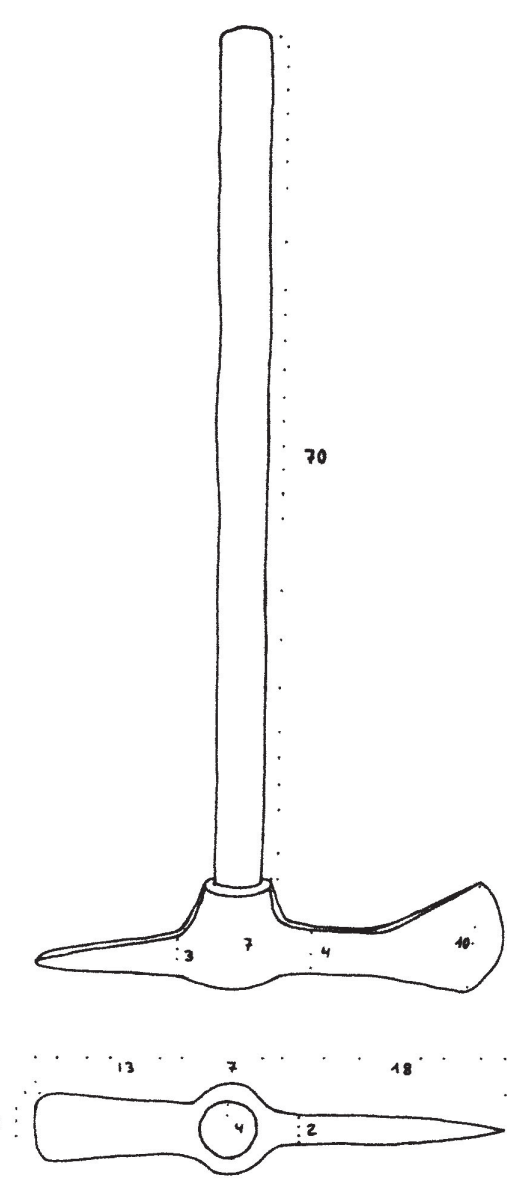

MONTERO
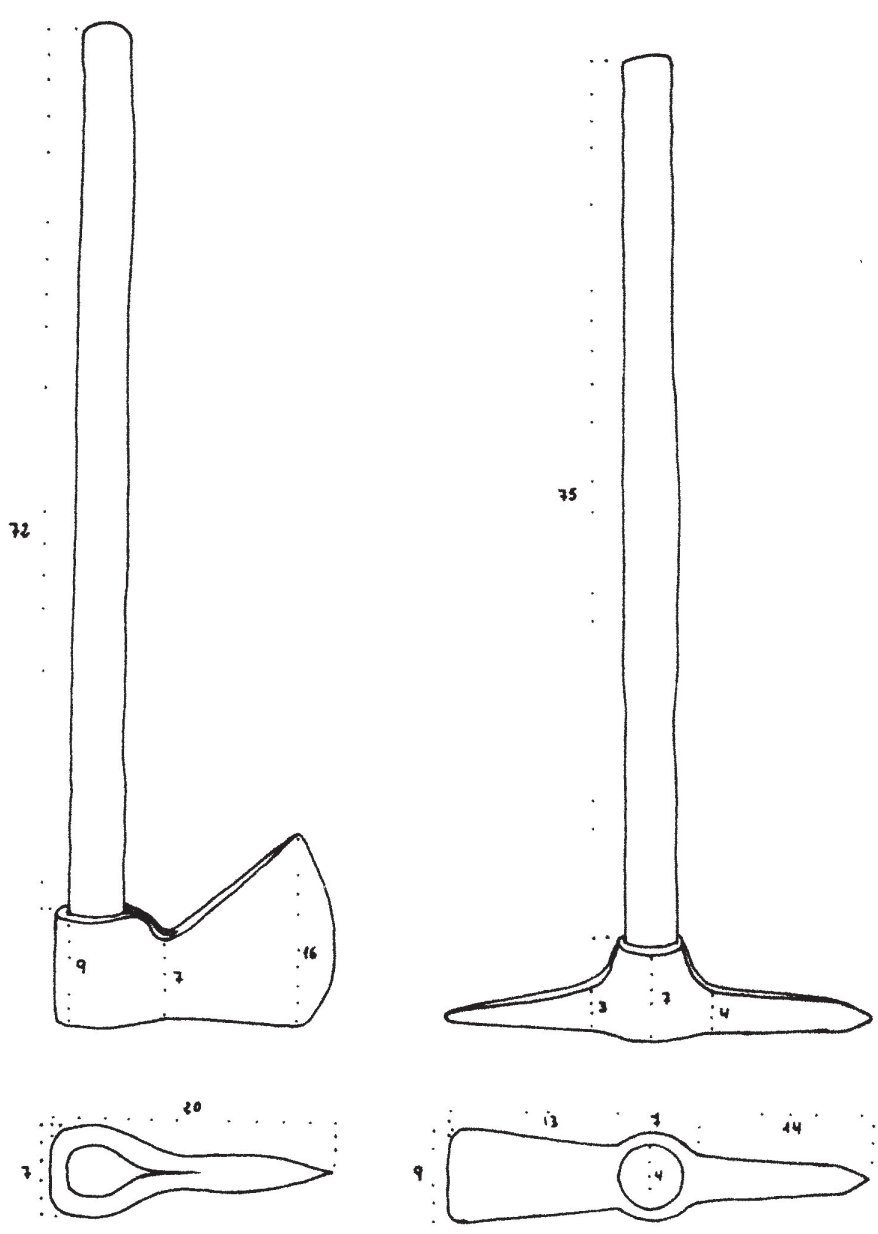

HACHA

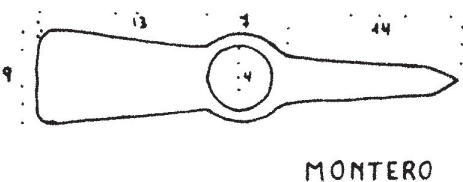

Fig. 4. Aperos utilizados en el cultivo de la viña.

La cava de hoyos u hoyas se llevaba a cabo a comienzos del invierno, dejando que la tierra se orease hasta los meses de febrero o marzo, época en que se plantaba.

En cuanto a la naturaleza de las vides, había dos sistemas de plantación:

- Poner despunte. En los meses de noviembre o diciembre se cortaban de cepas escogidas por su calidad, los sarmientos más rateros o bajeros, a ser posible con barbas; con ellos se formaba vivero en la bodega, enterrando las cabezas para que echasen barbas, los que no las tenían, hasta febrero o marzo que era cuando se plantaban estos palos barbaos, colocándolos en el centro del hoyo, que se rellenaba con su propia tierra bien aireada y limpia de impurezas. 
- Poner estacas. Una estaca o cepa silvestre es una vid americana, cuyas raíces no son atacadas por la filoxera, pero no dan fruto y es necesario injertarlas. Se distinguen dos clases de estacas: riparia y rupestre. Se cortaba un tallo de una estaca y se plantaba sin más; «como estas cepas tienen mucha fuerza, agarran siempre».

En el caso de que se haya elegido el segundo sistema, cuando la cepa silvestre ha agarrado y tiene fuerza (pasados uno o dos años), debe procederse a su injerto; esta faena la hacen los propios labradores, cada uno injerta las suyas, aunque hay algunos que por su especial destreza son llamados por amigos o en algunos casos trabajan asalariados.

El injerto se hace "cuando están llorando las cepas», o sea, en primavera al empezar a subir la savia. Unos quince días antes de injertar se cortan los sarmientos elegidos que deben tener las leguas largas (legua es la distancia que va de nudo a nudo), mientras que los de nudo corto, como por ejemplo el garnacho, se considera que se injertan peor. Nada más cortarlos, se preparan las pipas, trozos de los sarmientos de una cuarta de longitud y rebajados por su extremo más grueso con una navaja hasta formar una cuña, se meten en un recipiente con agua donde permanecen hasta el día en que se injerten.

Se arrancan todos los tallos de la cepa silvestre menos uno, el más fuerte, que se corta a ras de tierra con la hoz o las tijeras; con la navaja o chaira se abre por la mitad, se mete la pipa, se ata con un junco o rafia y se le hace un acobijillo de tierra húmeda con la mano, que tape el injerto pero que deje al aire las yemas de la pipa, de las que brotarán hojas y ramitas.

En casi todos los planteles «se perdían» algunos palos y había que reponerlos. Si la pérdida se producía en los dos o tres primeros años se volvía a plantar como si fuese nuevo, pero si era posterior se reponía por mugrón. En la cepa más próxima se dejaba un rastro o mugrón en dirección al espacio vacío en el que se enterraba cuando era suficientemente largo y fuerte, dejando su extremo al descubierto, del cual saldrán las hojas, mientras que de la parte enterrada lo harán las raíces. Cuando el mugrón ha agarrado se corta y separa de la cepa madre.

\section{LA CEPA}

Las vides jóvenes, antes de que den fruto, se denominan palos; a partir de los tres o cuatro años son cepas. Como hemos visto anteriormente, las vides americanas son cepas silvestres o estacas. Las cepas de gran tamaño son cepas frondosas o cepas con mucho vicio. 

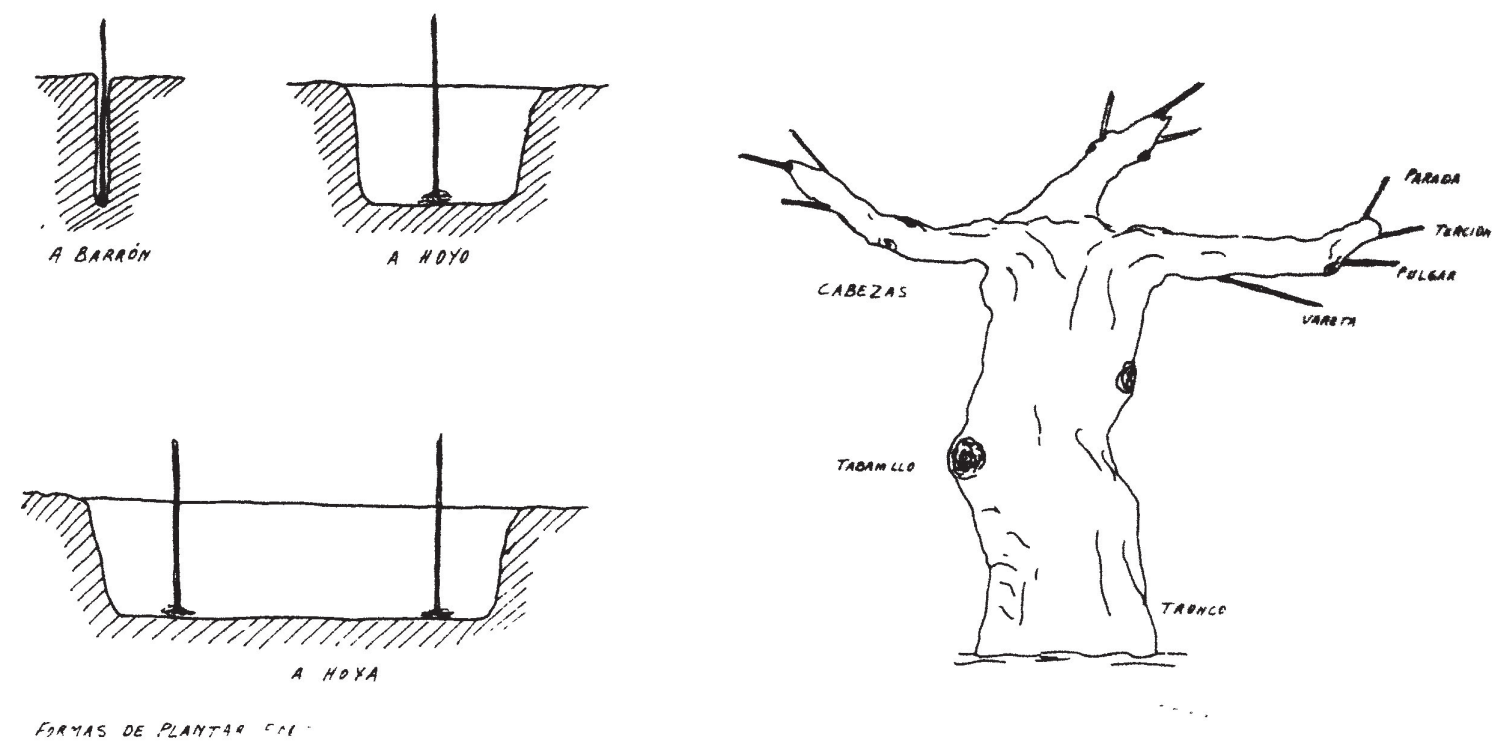

Fig. 5. Cepa y formas de plantar los palos.

Partes de una cepa:

- Las raíces son de dos clases: someras son las superficiales, finas y perjudiciales, por lo que se quitan. Las profundas son fuertes y beneficiosas porque captan bien la humedad durante la época seca.

- La parte aérea consta de tronco, que suele ser corto y por eso las cepas en la Ribera son bajas; cabezas, son los brazos gruesos que salen del tronco (se dejan tres o cuatro, según la fuerza de la cepa y se procura que abran, es decir, que crezcan en horizontal); las ramas que salen de las cabezas se llama tallos cuando están verdes ( $\mathrm{y}$ la cepa tiene tallerio), sarmientos cuando secos o recién cortados (la cepa con muchos sarmientos se dice que lleva mucha leña) y podas la parte de los sarmientos que queda en la cepa al podarla. Se suelen dejar tres podas en cada cabeza que reciben los nombres siguientes: parada, es la poda más alta; terción, la intermedia, y pulgar, la más baja (fig. 5).

La parte del sarmiento entre dos nudos es una legua; los que tienen leguas cortas se llaman de nudo corto. Los zarcillos se conocen como borquillas.

La savia es el lloro, y «llorar la cepa» es subir la savia. La cepa que se seca o se echa a perder es porque tiene malilla.

La tierra plantada de palos, o sea de cepas nuevas, se llama los palos; cuando ya son adultas se denominan viña o plantel. 
La vida y productividad de las cepas depende de los cuidados que se les presten: si está bien atendida al cuarto año ya da fruto (cada 500 cepas dan un cesto, unos 120 kilos); a partir del séptimo año su producción ya es plena. Su vida es larga: unos setenta u ochenta años a pleno rendimiento; a partir de aquí van envejeciendo y su rendimiento, por mucho que se las cuide, desciende poco a poco.

Clases de cepas más frecuentes:

- Del país. Es la que mejor se adapta a las características de la región: madura pronto y bien y da una uva muy pequeña y muy dulce, tanto lo blanco como lo negro. En estos últimos años está en regresión porque se prefieren otras clases que producen mayor cantidad, pero que no llegan a madurar y dan un vino de mala calidad.

- Garnacho. Da mucha cantidad pero sin calidad; lo hay blanco y negro.

- Valenciano. Es negro, de uvas muy gordas, «como ciruelas», que forman grandes colgajas.

- Pirulés. Es blanco, de uvas doradas o verdes cuando está en sombrío. Requiere terrenos arenosos.

- Tinto aragón. El nombre indica su origen y cualidades; quizá se introdujo en esta zona para aumentar el grado del vino.

- Tintorero. Es negro, de uvas pequeñas y muy rojas, que tienen, como su nombre dice, un mosto muy colorado.

- Moscatel. De uvas negras y grandes que forman racimos apiñados y de pezón muy duro.

\section{Trabajos en la viña. Ciclo anual}

Durante los tres primeros años de vida requiere poca atención; lo fundamental era:

- Estar atentos a las pérdidas y reponerlas como se dijo.

- Cavar todo el plantel una vez a finales de primavera con el azadón (en los últimos años ararlo con el arado viñero) y mantenerlo sin hierbas.

- Cebar los palos cuando cumplían los dos o tres años: se cavaba una boyeta alrededor del tronco hasta las raíces someras, las cuales se remondaban para que tirase hacia abajo; en cada hoyeta se echaba un poco de basura (estiércol) al pie del tronco (una cesta de basura se repartía para cuatro cepas) y se tapaba con 
la tierra extraída; si por casualidad se levantaba viento solano antes de tapar las hoyetas, se dejaban al descubierto hasta que éste cesase, pues si se hacía con dicho viento soplando, las cepas no darían nada de uva. Esta operación se hacía en invierno.

- Al segundo o tercer año se encabezaba la cepa, es decir, se organizaba la poda, quitando leña del centro para que abriera hacia afuera.

A partir del tercer año había que realizar todos los trabajos del ciclo que veremos a continuación:

- Esvastagar en otoño. Consiste en cortar con la hoz o las tijeras los sarmientos que no tienen yemas o que no se piensa dejar para el año siguiente. Los que se dejan se pueden esvastagar en largo, dejando al sarmiento con todas sus yemas, o esvastagar en corto, dejándole seis u ocho yemas únicamente. Hay partidarios de ambos sistemas: si se hace en corto, los tallos que broten al año siguiente tienen más fuerza pero corren peligro de helarse si cae una helada tardía; si se hace en largo, los brotes tendrán menos fuerza pero nunca se hielan todas las yemas.

- Chiscar o tirar acobijos. Cuando se terminaba la sementera de otoño se ocupaban los meses de diciembre y enero en retirar del tronco de las cepas los grandes conos de tierra amontonados sobre ellos al empezar el verano; así se ventilaba el tronco y penetraba mejor el agua de las lluvias primaverales. Esta tarea se hacía con el azadón raso si la tierra era arenosa, o con el azadón de picos si era cascajo. Hoy día, en lugar de chiscar, se aran las calles hacia fuera con el arado viñero.

- A la vez que se chiscaba se recebaban cada dos o tres años, según las posibilidades del labrador, las cepas con basura.

- Al chiscar se aprovechaba para quitar la cascarilla del tronco con la mano, ya que aquí se cría el cuquillo, y se arrancaban los nietos o erpes (retoños que salían en el tronco y perjudicaban a los sarmientos).

- Podar o espuntar. Desde enero o finales de diciembre hasta marzo se lleva a cabo esta tarea, que antes se hacía, lo mismo que la de esvastagar, con la boz: este utensilio lo fabricaba el herrero del pueblo y consta de (fig. 6): gavilán, para cortar hacia arriba; cuchilla, para tarjar (cortar hacia abajo) y peto, para rebajar las cabezas.

Otro utensilio que llevaba el podador era un serrucho curvo (fig. 6) para serrar las cabezas en mal estado. Ahora se utilizan 

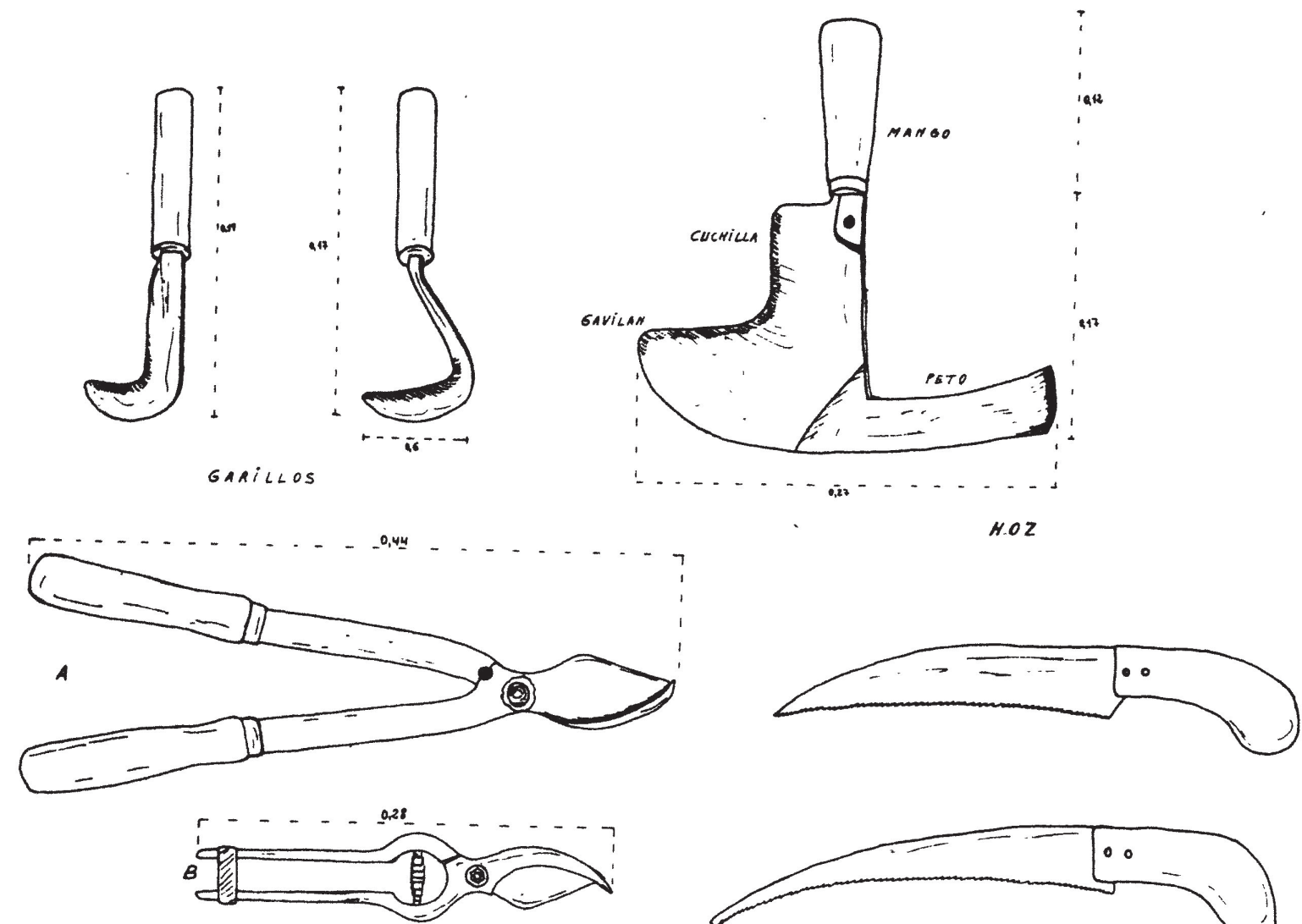

TIJERAS QEPDOAR(A) Y DE ESPUINTAR(B)

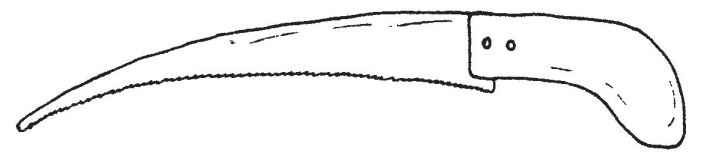

Fig. 6. Instrumentos de poda.

las tijeras, de manillas largas, para esvastagar y las tijeras de espuntar, con manillas cortas y muelle, para podar; para rebajar las cabezas o cortarlas se usan la hoz y los serruchos o bien una hachilla.

$\mathrm{Al}$ espuntar sólo se dejan tres podas por cabeza (cuyos nombres ya hemos visto), y en cada una se dejan unas cuatro yemas; el pulgar se puede dejar más largo para que no suba la cepa sino que abra. Si la cepa tiene mucha fuerza se deja una vareta, que es un sarmiento nuevo de los que echa en la parte baja de las cabezas y que da mucha uva.

Con el peto de la hoz o la hachilla se quitan los tabanillos, nudos que se forman en el tronco o las cabezas.

- Sarmentar. Era tarea exclusiva de las mujeres de la familia (sarmentadoras) o de jornaleras. Cada una «lleva» una calle; en primer lugar elige un espacio libre de sarmientos en el que coloca tres vástagos (sarmientos muy largos) sobre los cuales irá depositando los puñados de palos que recoge, teniendo cuidado de que 
queden siempre culo con culo; culo o cabeza del sarmiento es la parte más gruesa, el extremo por el que estaba unido a la cepa. Cuando tiene suficientes para un manojo se atan con los tres vástagos presionando con la rodilla. Como es muy difícil hacer un nudo con los vástagos aunque estén verdes, se da una vuelta de uno sobre el otro y lo que sobra se entremete en el manojo, el cual se trenza por su parte más fina, mientras que en la otra los culos deben quedar perfectamente enrasados.

Los manojos se amontonan en la orilla más accesible del plantel, se acarrean a casa y se colocan en la tenada que hay, mejor diríamos había, en todos los corrales de donde se van tomando según se necesitan para quemar en la cocina.

- Entre los meses de marzo y mayo se cavaba todo el plantel con el azadón para quitar las hierbas y mullir la tierra de cara a las lluvias de primavera.

- A comienzos del mes de mayo se produce la floración de las cepas, cerner, y después la fecundación y formación de la uva, tirar la cierna; hay un refrán en el pueblo que sitúa con precisión este hecho: «Por la Cruz, la viña reluz».

- Azufrado. Para combatir el oídio, una de las peores plagas de la vid, se espolvorea azufre con la mano en las cepas cuando están cerniendo. Esta mano de azufre se repetía al salir los tallos y al pintar las uvas.

- Aporcar o acobijar. Se realiza desde finales de mayo hasta San Pedro y consiste en cavar de nuevo la tierra con el azadón y formar junto al tronco de cada cepa un acobijo, esto es, un gran montón de tierra de forma cónica que tape el tronco para que así se mantenga mejor la humedad durante el verano. De paso se quitan erpes o retoños perjudiciales. Sobre este trabajo existe un refrán que dice: "Cuando canta la bobilla no te pongas a la orilla», cuya explicación es que cuando canta este pájaro, la abubilla, es señal de sequía y las orillas de los planteles tenían la tierra apelmazada y muy dura, por lo que su cava era más penosa. Ahora este trabajo se hace con el arado viñero; es lo que se llama arar para adentro, con lo que se pretende conseguir el mismo fin.

- Estallar. Se efectúa en el mismo tiempo que la operación anterior; es bueno para quitar las hojas malas, las que tengan orugas y los tallos que no llevan fruto. También es aconsejable quitar un poco de forraje a la cepa para que la uva aproveche mejor la fuerza y el sol pueda madurarla mejor. 
- Binar o esbrincar. En agosto se quitaban las hierbas con la zuela, también se sulfataban las cepas para combatir el mildiu antes de que las uvas comiencen a birriagar; el sulfato se disuelve en agua y se asperja con una escoba vieja sobre las hojas.

A mediados de agosto comienzan las uvas a birriagar y uvas birriagadas lleva San Roque en la mano cuando es sacado en procesión los días 15 y 16 de dicho mes. En Hoyales, por ejemplo, es San Bartolomé quien pasea las uvas y protege la cosecha. En pocos días las uvas pasan de estar birriagadas a pintadas y a maduras, lo que sucede a primeros de septiembre. Esta maduración se atribuye sobre todo a la luna llena de agosto, a lo que alude esta coplilla:

\author{
Quítate del sol que quema \\ y de la luna que abrasa, \\ y de las murmuraciones \\ nadie sabe lo que pasa.
}

Cuando las uvas ya se podían comer se acotaban los caminos, para que nadie saliese al campo, colocando en ellos, a la salida del pueblo, un mojón o montón de piedras; varios guardas contratados y los de ayuntamiento se encargaban de vigilar que esto se cumpliera. Esta costumbre estuvo vigente hasta los años cuarenta.

Día de la licencia. Mediado el mes de septiembre, los dirigentes municipales elegían un día en el que todos los habitantes del pueblo podían acudir a sus viñas para ver el grado de madurez de la uva y, de paso, cortar unos pocos racimos para comer; en cada camino había durante todo el día un guarda que vigilaba que nadie se excediera y trajese más racimos de los cuatro o cinco permitidos. Los chicos aprovechaban este día para salir al campo a comer uvas y andaban merodeando de un lado para otro, robando racimos o cazando pájaros, confundidos entre el ir y el venir de los campesinos.

\title{
5. LA VENDIMIA
}

La fecha del comienzo de la vendimia variaba cada año en función del clima, del cual dependía la maduración temprana o tardía de la cosecha; era fijada por una junta de todos los vecinos del pueblo, que se reunía en domingo, después de la misa mayor, y para ello se basaban en lo visto el día de la licencia. Ningún vecino podía comenzar antes ni después. Esta costumbre es de origen medieval, según podemos ver 
por una sentencia que dio la reina Doña Violante, viuda de Alfonso $\mathrm{X}$, en el monasterio de Valbuena en $1295^{1}$.

El trabajo, sin embargo, no comenzaba propiamente el día fijado para vendimiar, sino que desde una semana antes todo el pueblo entraba en acción con el fin de:

- Dejar limpios los lagares, especialmente las pilas, que se lavaban con agua abundante y se fregaban con escobas.

- Lavar por encima las cubas, ya que la limpieza a fondo se había hecho al desocuparlas; entonces un hombre se desnudaba, se metía dentro de la cuba y la fregaba con agua caliente hasta que el agua salía totalmente clara.

- Remojar los cestos para que recuperasen algo de su elasticidad. Los cestos son unos recipientes cilíndricos o ligeramente troncocónicos, de mimbre sin pelar, en los que se transportaba la uva desde la viña al lagar. Su cabida normalmente era de unos 120 kilos de uva (unas cinco cántaras de vino); algunos eran mayores, de hasta 180 ó 200 kilos, pero éstos eran muy difíciles de cargar. Casi todos los del pueblo sabían hacerlos con los mimbres o bimbres de las mimbreras que abundan en las lindes de huertos y tierras, se cortaban en enero estando la luna en cuarto menguante para que no se apolillasen. Los que no querían hacerlo o no tenían tiempo los encargaban a tres o cuatro familias que, por no tener mucha labranza, estaban especializados en este trabajo, o bien a los gitanos que todos los años acudían por estos días; también se vendían en el mercado de los sábados en Aranda.

1 Esta sentencia la transcribe LOPERRáez CORVALÁn, Descripción bistórica del Obispado de Osma (Madrid, 1788), tomo III. Cito por la edición facsímil de Madrid, 1978, que en la p. 232 dice así: «Otrosi, oviemos por bien mandar en rason de la vendimia, que ninguno non vendimien en los pagos de la Viella, nin de las Aldeas fasta que el Conceio acuerde de lo deromper, e lo que fuere de pago que lo pueda vendimiar cada uno quando se quisiere, e facer dello su pro. Er los tres Miercoles, que suelen facer para vendimiar antes que se rompa, que los haian ansi, como lo siempre usaron: e si alguno de los pobres ovieren menester de socorrer dello, e ovieren ommes que vayan al Conceio a mostrargelo, que fagan gracia, e gelas degen vendimiar, e tomar dellas quanto quisieren para facer dello su pro. Et a qualquier cuemo estos que lo ovieren menester, e lo haian de alcanzar, que les fagan esta gracia; e qualquier que en otra manera vendimiare, o lo levantare, o vendiere, que sea con la penna, ansi como lo usaron fasta aqui. Otrosi, tengo por bien, e mando, que despues que todas las vinnas fuesen vendimiadas de la Viella, e de las Aldeas, que puedan pastar con sus ganados los de las Aldeas, cada uno en la suia, e que no les prendan, nin les fagan mal ninguno por ello...». La villa a la que el texto se refiere es la de Roa y las aldeas son las que formaban su Comunidad de Villa y Tierra. 
- Anunciar en el mercado de Aranda la fecha de la vendimia, para que acudieran vendimiadores y acarreadores de fuera, al ser insuficientes las personas del pueblo para el trabajo intensivo de la vendimia. Procedían de los pueblos segovianos de La Serrezuela y de la Sierra de Ayllón, o de los burgaleses del Valle de Esgueva. Curiosamente en verano el movimiento tenía signo contrario, pues los segadores de la Ribera acudían a tierras segovianas o del Valle.

La víspera de la vendimia iban llegando los forasteros a la plaza donde se contrataban con algún labrador del pueblo; muchos conocían a éstos por ser habituales todos los años y se dirigían directamente a su casa a ofrecer sus servicios. Vendimiadores y acarreadores eran contratados «a tanto y mantenido». El «tanto», antes de la guerra del 36, era de unos siete reales para los vendimiadores y la manutención comprendía el aguardiente de la mañana, el almuerzo (patatas con bacalao) y la comida (garbanzos con tocino y chorizo) en la viña, la cena en casa y un lugar para dormir en el pajar. Los acarreadores venían con su carro y su yunta de bueyes o machos, o bien con un burro y su albarda sobre la que llevaban dos cestos (fig. 7) menores de lo normal, que contenían una carga (16 arrobas y traducido a vino 8 cántaras; la cántara en la Ribera tiene y tenía 16 litros).

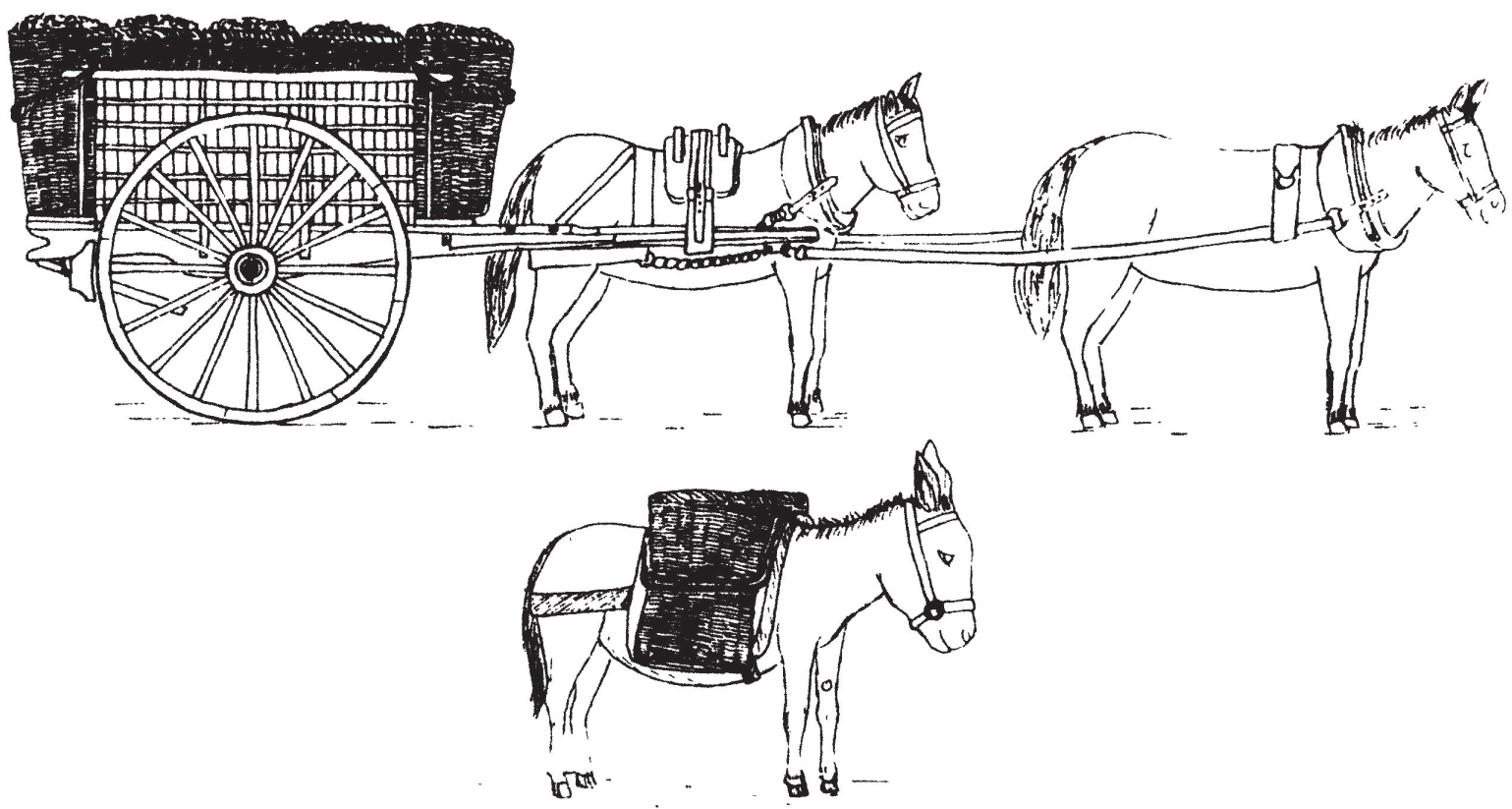

Fig. 7. Acarreo de la uva. Castrillo. 
En la misma plaza había mercado de los alfareros de Peñafiel y de hortelanos de los pueblos del Riaza que vendían sobre todo pimientos rojos; por la noche el ambiente era de fiesta. Todo el pueblo subía a las bodegas a merendar ensalada de pimientos rojos con bacalao o arencas y después había baile en la plaza.

La vendimia propiamente dicha duraba solamente cuatro o cinco días que transcurrían de la misma manera. Al amanecer toda la familia, incluidos niños, y los vendimiadores contratados marchaban a las viñas con el carro, cestos, cestas y cunachos, ropa... Si había mucha aguada se esperaba un poco a que saliera el sol. Las mujeres quedaban en casa preparando el almuerzo y la comida; a media mañana, hora de almorzar, estaban en la viña y el resto del día ayudaban a vendimiar. Cada vendimiador llevaba una cesta de mimbre con dos asas, hechas en el pueblo como los cestos, o un cunacho o canasto de tiras de castaño; en ellos se dejaban los racimos que se cortaban con el garillo, también conocido como garullo, y cuando estaba llena la cesta, cada vendimiador la llevaba a los cestos que estaban en el suelo, alineados en una orilla de la viña en los que se iba depositando la uva. El trabajo sólo se detiene para almorzar y comer; se enciende una chisquera con sarmientos para calentar la comida y las manos si el día está fresco; se forma un corro con la olla en el centro y todos van metiendo la cuchar, siguiendo un turno más o menos establecido implícitamente, mientras en la otra mano se sujeta un gran trozo de pan. Entre vuelta y vuelta el barril o el botín pasa de mano en mano y aunque se come despacio, se habla poco. Terminada la comida hay un rato de descanso para «echar el cigarro", hablar de lo buena o mala que viene la cosecha, hacer lagarejos o gastar bromas a los serranos, que tenían fama de palurdos.

Cuando al sol «le quedan un par de dedos» ${ }^{2}$, es hora de enganchar la yunta al carro y cargar los cestos. En Castrillo no hay cargaderos en las viñas como en otros pueblos de la Ribera ${ }^{3}$, por lo que es preciso levantar los cestos llenos, desde el suelo hasta el carro. Esto lo hacen entre tres hombres fuertes: uno se sube al carro y allí recibe los cestos, los otros dos levantan los cestos pasando por el culo de éstos un palo resistente que sujetan con una mano, mientras con la otra sostienen la

2 Los campesinos calculan el tiempo que falta para ponerse el sol extendiendo el brazo y poniendo la palma de la mano, que mira a los ojos, entre éstos y el horizonte. Así se cuentan los dedos que caben entre el horizonte y el sol; cada cuatro dedos es una hora.

3 El cargadero es un montón de piedras y tierra, con rampa por un lado y caída vertical por el otro, en el que se coloca el carro. De esta manera se carga con facilidad. 
panza del cesto; están en cuclillas en la posición descrita, a una voz se ponen en pie y a otra elevan el cesto hasta la zaga del carro, donde es recibido por el que está arriba. En cada carro se transportan diez cestos (fig. 7) si las zagas son amplias; como sobresalen se aseguran con sogas.

Al anochecer las calles del pueblo, desiertas y silenciosas durante el día, se llenan de voces, trallazos y el cantar de carros y carreteros camino de los lagares.

Terminada la vendimia, se acotaban los planteles con unos grandes montones de tierra cubierta de cal en las esquinas. Durante un par de semanas no podían entrar ovejas ni otro ganado, porque eran los días del rebusco. Las rebuscadoras eran mujeres pobres del pueblo o de pueblos de la sierra que venían con borricos y que acudían con sus hijos pequeños a cualquier viña, pues había total libertad de entrar en tierras ajenas durante estos días a recoger las colgajas o agraces que habían quedado en las cepas. Después podían entrar ya los rebaños a carear las viñas, pero cada cual a las de su propiedad; los que no tenían ovejas cedían, a veces, el careo a algún pastor a cambio de alguna compensación en forma de basura de oveja, jirle, o de quesos que se entregaban el día del Corpus.

Otros términos léxicos en relación con la vendimia:

- Uva, cada grano que compone el racimo, pero también es el conjunto de fruto de la vid o la cosecha entera.

- Sollejo, la piel de la uva, el hollejo.

- Carne, la pulpa de la uva.

- Mosto, el zumo, y los pipos las simientes de la uva.

- Rampujo, el escobajo del racimo.

- Pezón, la unión del escobajo al sarmiento.

- Cogaja o colgajo, una parte del racimo o un racimo muy pequeño.

- Granujas o desgranadas, se dice de las uvas sueltas.

- Apiñaos, se llama a los racimos de uva muy junta.

- Ralos o de uvas escarriadas, de los de uva clara.

- Agraces, las colgajas sin madurar.

- Pasada, se dice de la uva muy madura.

\section{LOS LAGARES}

Son edificios rectangulares de un solo cuerpo de altura, con cubierta a dos aguas y el caballete del tejado paralelo a los lados mayores. Visto desde el exterior destaca el grueso paredón que se levanta en un ex- 
tremo como medio metro por encima del tejado: es la carga, que sirve de contrapeso a la prensa y que rompe la monotonía de las líneas exteriores y da gracia y personalidad al edificio. En el extremo opuesto, en el lado menor o en uno de los mayores, está la puerta, de dimensiones modestas. Toda la construcción es de piedra de mampostería trabada con mortero, excepto en esquinas y vanos en que aparece la sillería.

La mayoría de los lagares son exentos y están agrupados en los alrededores de la Cuesta de las bodegas, promontorio que se alza al este del pueblo pero unido a él, en el que están excavadas las bodegas donde se conserva el vino; lagares y bodegas forman un barrio bien diferenciado del resto y con rasgos propios.

En planta (fig. 8) el lagar se compone de una gran pila, pilón, en la que se deposita la uva a través de uno o dos portejones abiertos a un metro sobre el nivel de la calle, más o menos la altura de la zaga del carro. El pilón es todo él obra de mampostería, cuyas paredes, paneras, están revocadas de mortero y levantan alrededor de metro y medio sobre el nivel del suelo del lagar. La pila es más pequeña y está excavada en el suelo, con paredes de piedra revocada de mortero; a ella cae el vino desde el pilón por el chorrete, que es un canalillo horadado en una gran piedra embutida en la panera que separa el pilón de la pila.
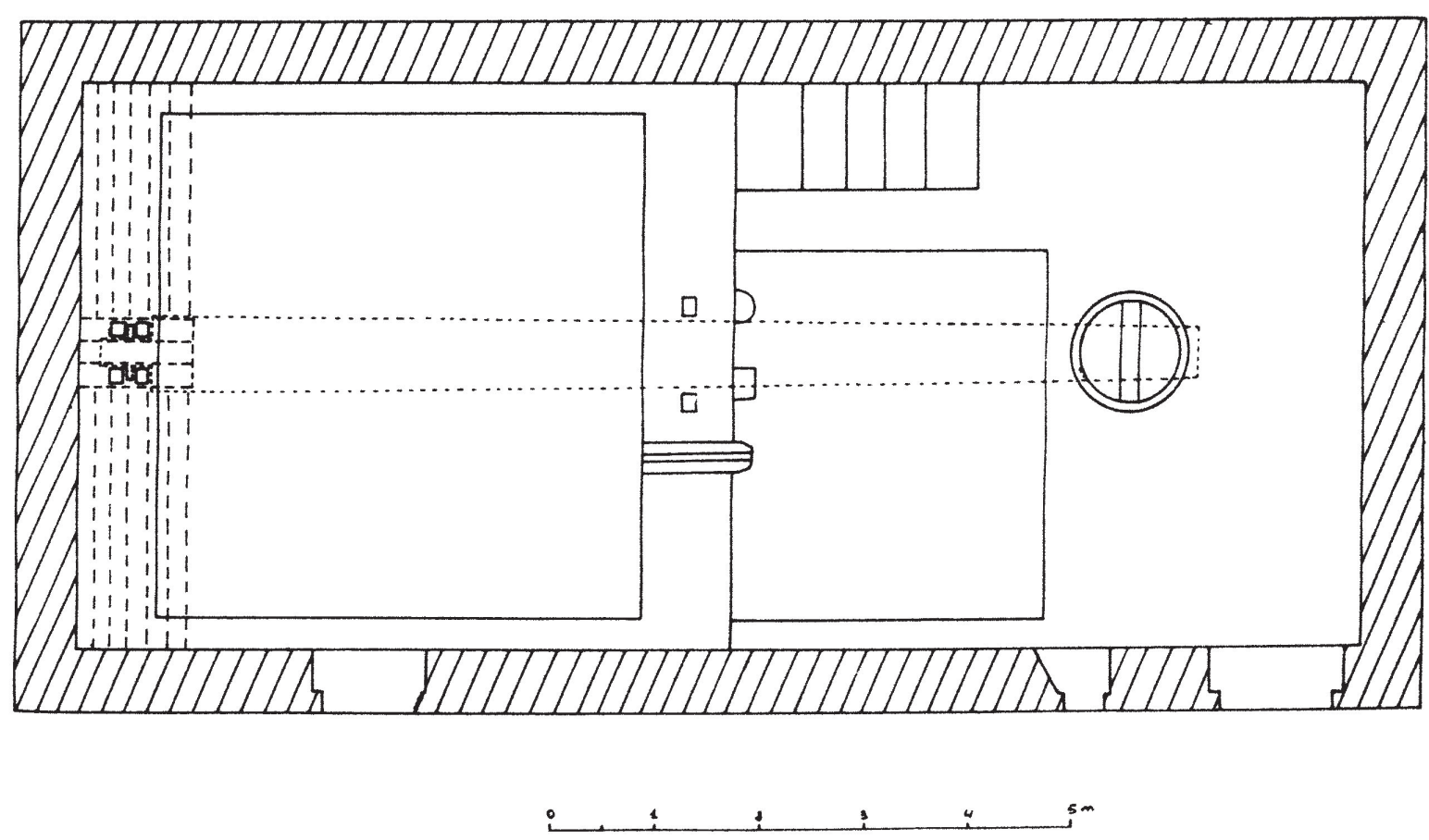

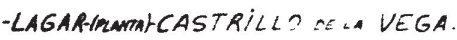

Fig. 8. Planta de lagar. 
A un lado de la pila hay unas escaleras de piedra para subir hasta el pilón; sin embargo, en Castrillo no conozco ningún lagar que las tenga para bajar a la pila, cosa frecuente en los de otros pueblos de la comarca. Entre la pila y la puerta queda un espacio en el que descansa la piedra lagar y un pozal en el que se vierte el vino de la pila con el que se llenarán las pellejas.

La iluminación interior es deficiente y no es mejor la ventilación, aunque se conseguía mantenerlo libre de gases perniciosos, producidos por la fermentación, gracias a la corriente de aire que se producía entre puerta y portejones, que estaban abiertos constantemente.

La prensa propiamente dicha se compone de:

- Viga, grueso tronco de un olmo sin desbastar; en su base tiene una espiga, llamada coz, que se introduce entre las bareñas, cuatro postes entre la panera de la coz y la carga que sirven de guías a la coz. Esta tiene un agujero por el que pasa el pastor, madero que impide a la coz desplazarse en sentido horizontal; pero sí puede hacerlo verticalmente, pur eso entre ella y la carga se co-

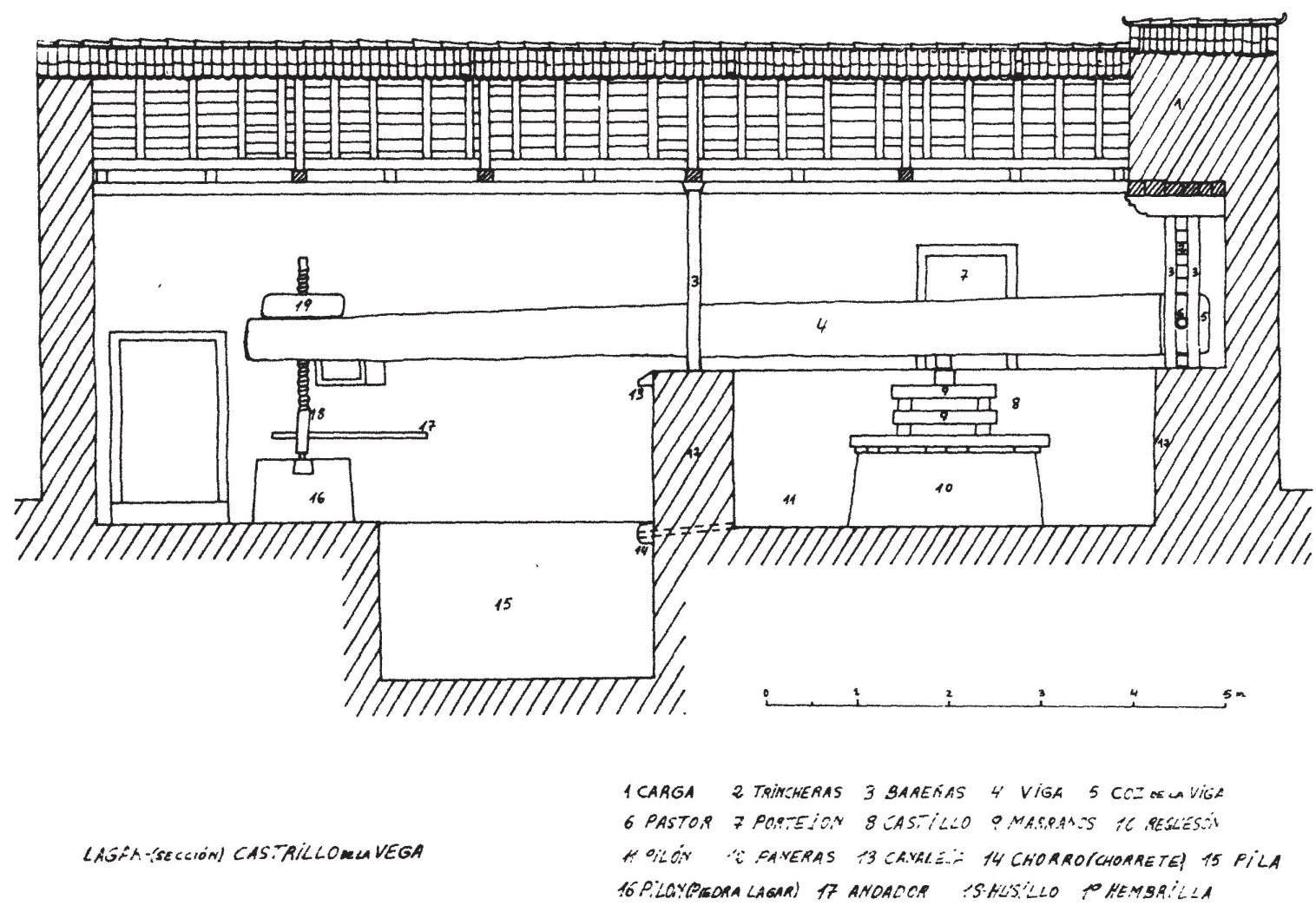

Fig. 9. Sección de un lagar. 
locan, cuando funciona la prensa, las trincheras, pequeños maderos que transmiten el empuje de la viga a la carga.

- Piedra lagar o pilón, gran piedra troncocónica que hace de contrapeso, unida por un pasador férreo al husillo. Este es un tornillo de madera, atravesado en su parte inferior por el andador, palo muy largo para girar el husillo, y que a su vez atraviesa el extremo delgado de la viga y enrosca en la hembrilla, pieza unida a dicho extremo.

- Castillo, construcción en forma de torre que se levanta sobre el requesón (montón de uva pisada y dispuesta para ser prensada). El castillo consta de unos gruesos tablones sobre la uva, y de los marranos, gruesos maderos escuadrados que forman la torreta sobre la que cae el peso de la viga y la piedra (fig. 9).

El régimen de propiedad más frecuente era el de varios aparceros, cada uno de los cuales poseía cierto número de cargas en ese lagar, y que puede depositar él, o bien arrendar o ceder a otro aparcero o a uno que no lo sea. El aparcero con mayor número de cargas, propias o arrendadas, era nombrado mayoral cada vendimia ya que no siempre era la misma persona; más adelante hablaremos de sus funciones.

Desde el pasado siglo se construyeron pequeños lagares y lagaretas de propiedad individual que permitían mayor libertad de decisión sobre el propio vino; algunos atribuyen esta tendencia a la pérdida del antiguo espíritu de solidaridad y a los enfrentamientos políticos.

Delante del portejón del lagar se montaba un andamio con unos burros y unos tablones sobre ellos, sobre el que se descargaban los cestos. Allí está el romanador, que es uno de los aparceros, para arromanar o pesar los cestos y apuntar el número de cargas que deposita cada aparcero. Para este menester se utiliza una rudimentaria romana que consta de un madero incrustado en la pared, de la que sobresale medio metro, sobre el que se coloca otro de unos tres metros de largo; de un extremo pende el cesto de uva por medio de sogas y del otro un gran peso. Los dos maderos que forman la romana llevan en su intersección unas clavijas para evitar el deslizamiento de uno sobre el otro.

Los cestos pesados se vaciaban en el pilón, en el que se iba almacenando toda la uva hasta que terminaba la vendimia. Inmediatamente se iniciaba la pisa: los pisadores, con los pies descalzos y los pantalones arremangados o sin ellos, van dando vueltas por el pilón con pisadas enérgicas durante dos horas por la mañana y otras dos por la tarde; de vez en cuando se revolvía con el andador. Esto se hacía durante unos quince días en los que se efectuaba la primera fermentación estando 
el mosto en contacto con hollejo y rampujo; este método tan elemental era una de las causas de la baja calidad del vino ${ }^{4}$.

Pasado el tiempo indicado, se probaba el líquido: si su sabor no era dulce la fermentación había terminado y se procedía a dar el taponazo, es decir, quitar el tapón del chorrete para que el vino cayese a la pila; este primer vino era el clarete, que salía en la proporción de una cántara por cada carga, aproximadamente.

Cuando había escurrido todo el clarete, comenzaba el prensado. Con palas de hierro o con garias se amontonaba en el centro del pilón la uva pisada formando un requesón circular y apelmazado sobre el que se montaba el castillo. La viga está lo más alta posible, las trincheras entre la coz y la carga, y la piedra en el suelo. En cuando se terminaba de montar el castillo, dos o tres hombres se agarraban al andador y levantaban la piedra: la prensa entra en funcionamiento.

El primer vino que salía del prensado era el ojo de gallo, algo más oscuro que el clarete, de color guinda; el resto era tinto.

En el lagar estaba siempre alguno de los aparceros, que se encargaba de abrir la canaleja, o sea, dar un corte de vez en cuando con una pala en la pared delantera del requesón para que saliera más fácilmente el vino, y de vigilar que no se sentase la piedra; si ésta bajaba mucho - llegaba a sentarse, había que ganar trinchera, es decir, poner más trincheras entre la coz y la carga; para ello era preciso levantar la hembrilla, luego la punta de la viga y así bajaba la base donde está la coz, meter las trincheras y volver a levantar la piedra. Todos los días por la mañana y por la noche se cortaba el pie del requesón: se desmontaba el castillo, se recomponía el requesón y se volvía a montar. Y esto hasta que no salía una sola gota. Toda la actividad del pueblo giraba estos días en torno a los lagares y al vino nuevo.

4 A comienzos del siglo XVI cuenta Alonso de Herrera: «Dice el Crecentino, que en algunas tierras usan a pisar las uvas, y con sus escobajos las echan a cocer en sus tinas, lo qual el mucho reprehende, y con razón. No es menos lo que yo vi en un lugar que llaman Santa María del Campo, que tienen en casa sus lagares, en que caben quarenta, o cincuenta carretadas de uva, y hasta que se hinche aquel lugar, o jaraiz, echavan en el quanta uva tenian de dos o tres viñas no lo pisaban y estava alli la uva entera con sus escobajos, hojas y agraces, estando assi tanto tiempo cubriase toda de moho, que no avia quien sufriesse el hedor al tiempo que lo pisavan, y de aquella manera sale el vino mohoso, y del mucho verde, por los escobajos y hojas, acedo de los agraces, y hediondo de toda aquella mezcla mala, y en verdad mejor para derramar en la calle, que para bever». Agricultura General (1513) (Edición del Ministerio de Agricultura: Madrid, 1981, p. 129). El texto se refiere a un pueblo burgalés, Sta. María de: Campo, situado a unos $50 \mathrm{kms}$. al norte de la Ribera del Duero. 


\section{LAS BODEGAS}

En la Ribera del Duero hay dos tipos de bodegas: el primero es el de las excavadas en el subsuelo de las viviendas como sucede en Roa o Aranda ${ }^{5}$; el segundo el de las excavadas en una ladera o cuesta próxima al pueblo, como es el caso de la mayoría de los núcleos de población y, en concreto, el de Castrillo.

Muy brevemente expondremos sus principales características:

- Forman un espacio diferenciado: la cuesta de las bodegas.

- Constan de dos partes (fig. 10): a) Parte excavada en el terreno (arenas blandas sobre las que hay una capa de arcillas impermeables).

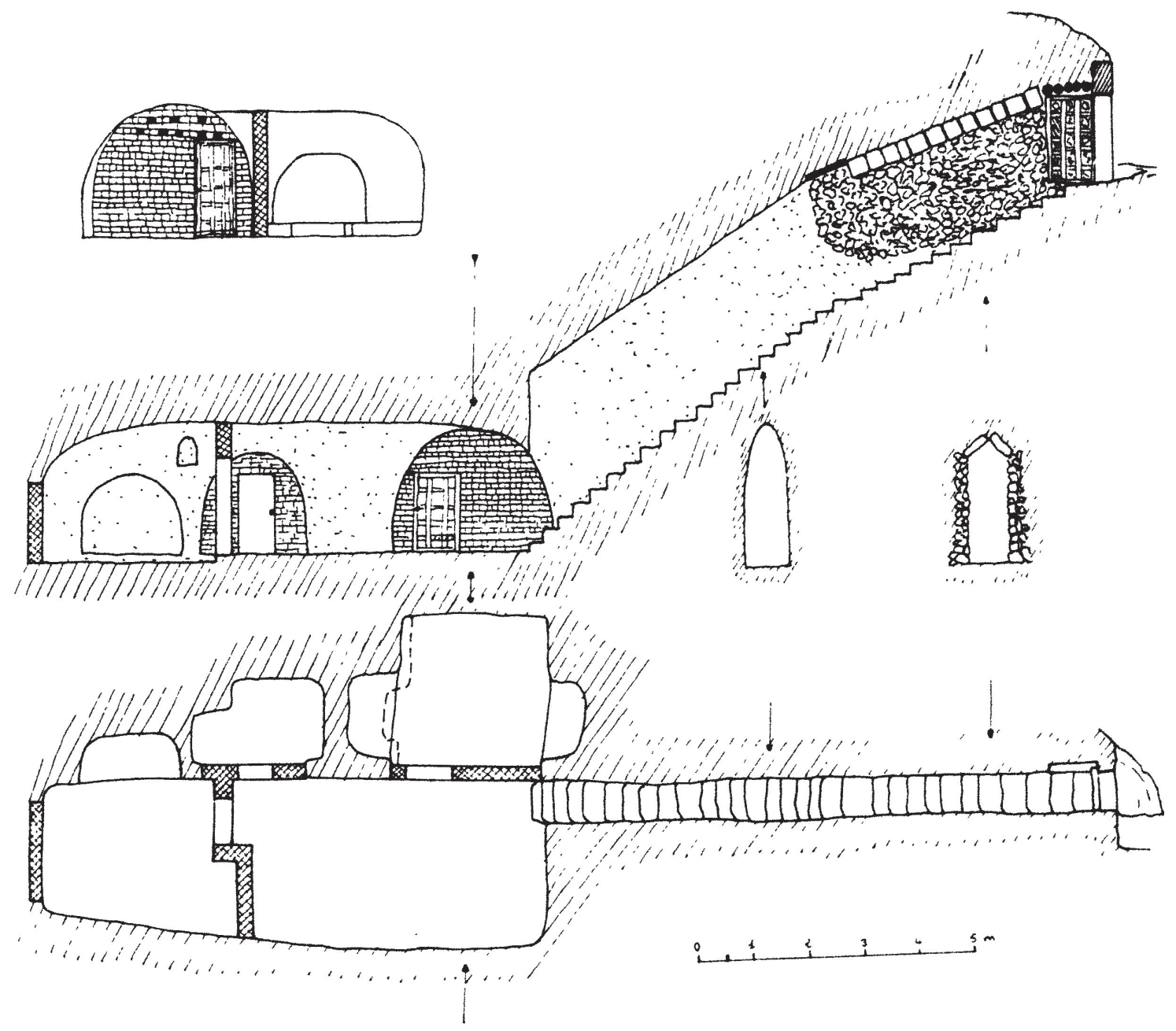

Fig. 10. Bodega de Castrillo de la Vega.

5 Sobre las bodegas de Aranda existe una publicación con abundante documentación: V. Iglesia Berzosa y A. Villahoz Garcia, Viñedo, vino y bodegas en la historia de Aranda de Duero (Burgos, 1982). 
b) Parte construida con piedra arenisca muy irregular. Se cubre con bóveda de losas en $\mathrm{V}$ invertida y en unos pocos ejemplares con bóveda de cañón. Sobre ella se deposita la tierra extraída, por lo que al exterior sólo se percibe la fachada con la puerta adintelada y alguna zarcera.

- Para su buena ventilación tienen una puerta de maderos entrecruzados y una zarcera ${ }^{6}$ o comunicación con otra bodega.

- La puerta siempre está orientada al norte, para evitar la entrada del aire solano, muy perjudicial para el vino.

- El sistema de propiedad es parecido al de los lagares: pertenecen a varios porcioneros, cada uno de los cuales posee un bodegón o un espacio para una cuba.

Antes de empezar la vendimia, como ya dijimos, se dejaban limpias y preparadas las cubas para recibir el vino, así que al tiempo que comenzaba el prensado también lo hacía la tira, es decir, el transporte del vino desde el lagar a la cuba. Los tiradores eran generalmente los mismos aparceros, pero en ocasiones se contrataban jornaleros; en este caso era necesario vender las gabelas, cierto número de cántaras, proporcionalmente al número de cargas que tuviera cada uno, para pagarlos. El mayoral, del que también hemos hablado, se encarga de acantarear, o sea, sacar el vino de la pila con un caldero que tiene un palo atado al asa y vaciarlo en el pozal que está al lado; además, se encargaba de llenar con un embudo y una mediacántara las pellejas en que se transporta el vino, así como de llevar la cuenta de las cántaras de cada aparcero por medio de tarjas, que eran unos cantos que se iban colocando en filas.

En cada pelleja (fabricada de piel de cabra por artesanos del propio pueblo) cabían tres cántaras, pero normalmente sólo se llenaban con dos, porque las bodegas quedaban, a veces, lejos del lagar y sus escaleras eran estrechas y oscuras. Las dos patas superiores de la pelleja, pelguillos, se ataban con una cuerda y formaban una especie de collar que el tirador sujetaba con la frente, que era la que aguantaba todo el peso; la mano izquierda cierra la boca, que no va atada para facilitar la rapidez en el vaciado y con la derecha se empujaba la barriga de la pelleja al tiempo que el tirador se aupaba y la levantaba («botar la pelleja»). Así cargado, con el cuerpo y ropa empapado y tinto en vino, el tirador

6 La zarcera consiste en un pozo vertical que comunica el fondo de la bodega con el exterior, que acaba en una construcción de piedra en forma de chozo de pastores, del que seguramente deriva, con dos o tres ventanucos en forma de saeteras. En los casos en que no existe zarcera, en el fondo de la bodega suele haber un boquete que comunica con otra y que permite la circulación del aire. 
emprendía rápida caminata por las sendas de la cuesta de las bodegas, hacia la suya haciendo sonar al andar las esquilas y changarras atadas a las piernas (cuya utilidad luego veremos). Bajaba las escaleras resbaladizas guiándose por el candil que alumbraba la boca de la cuba, a la que accedía por una escalerilla, y sólo tenía que colocar boca con boca y aflojar la mano izquierda.

Cuando en una bodega había una o dos cubas más o menos llenas, el vino comenzaba a cocer, segunda fermentación, y desprendía tufo (anhídrido carbónico) que se acumulaba a pesar de la corriente de aire entre la puerta y la zarcera y podía causar la muerte del que bajase. La señal de alarma la daba la llama del candil al apagarse; entonces se quemaban manojos de sarmiento para hacerlo desaparecer, pero al poco rato reaparecía. El peligro que corrían los tiradores era grande y ésta era la razón de las esquilas y changarras en las piernas; si dejaba de oírse su sonido cuando uno de ellos estaba en la bodega, era signo de que se había quedado privao y corría peligro de morir asfixiado. Inmediatamente alguien bajaba corriendo con una soga que ataba a la cintura del accidentado y con la mayor rapidez volvía afuera. Desde la puerta varios hombres sacaban a rastras al privao que, si bien sufría numerosos coscorrones, al menos salvaba la vida.

Este tipo de accidentes era frecuente, sobre todo al final, debido a las prisas por acabar y a que entonces, con casi todas las cubas llenas, el tufo era más abundante. Eran muchos los que bajaban conteniendo la respiración y trataban de estar arriba antes de que el gas les hubiese afectado, cosa que no siempre conseguían.

Las cubas se dejaban sin llenar del todo y para que no se saliera el vino al cocer se untaba con tocino rancio la boca, que de momento quedaba destapada. Para ayudar a la fermentación algunos añadían al vino huevos, manzanas, huesos... Cuando el vino se quedaba sereno porque había terminado la fermentación, se afinaba con gelatina, caldo de pezuña de vaca, nieve, sangre... Después se tapaba la boca con unas tablas y se sellaba con barro. Ya no se abriría hasta su venta o consumo.

\section{VENTA DEL VINO}

Ya dijimos al principio que el vino era el principal y casi único producto comercializable; no es extraño, pues, que toda la cosecha, excepto una pequeña parte para el propio consumo, se exportara a los pueblos de la sierra burgalesa (Huerta del Rey) o de la provincia de Segovia (Boceguillas, Prádena, La Hinojosa...). 
En el proceso de venta era imprescindible la figura del corredor. Era una persona del pueblo que había pujado más que otros candidatos en la subasta que remataba el Ayuntamiento. Su misión consistía en hacer de intermediario entre vendedores y compradores. Cuando algún vecino del pueblo quería vender una cuba, avisaba al corredor, el cual tomaba nota y lo apuntaba en la lista de espera; al llegar algún arriero en busca de vino, el corredor le llevaba a ver al primero de la lista en ese momento. Los tres iban a probar la cuba: el propietario abría la boca y con unos vasillos cataban el vino. Si al arriero le gustaba, se pasaba a ajustar el precio; ambos regateaban, con el corredor de hombre bueno, hasta llegar a un acuerdo y entonces «se abría la cuba»; por supuesto, si no se llegaba a acuerdo, el corredor llamaba al siguiente en la lista.

Para abrir la cuba había que hacer saltar el tapón de corcho que cerraba el canillero, agujero que está en el centro de la barriga de la cuba; para esto, que se llamaba «romper», se colocaba contra el corcho la canilla, hecha a navaja, de madera de nogal, y se golpeaba con un canto; el corcho saltaba hacia adentro y la canilla quedaba en su sitio mientras el vino caía por el agujero de ésta al pozal que estaba delante. La canilla se tapaba con el palo canillero, también de nogal; había canillas de hierro, hechas por el herrero en la fragua, que tenían una llave, palo canillero metálico que se dividía en dos: una parte quedaba tapando la canilla y la otra se desenroscaba y la guardaba su propietario.

Mientras se abría la cuba, los arrieros hacían la colambre a los pellejos de 8 ó 9 cántaras que ellos traían, lavándolos e inflándolos con un fuelle de palanca, para ver si se salían. A continuación se llenaban con el vino del pozal; el que envasaba iba cantando las mediacántaras que llenaba y otro las anotaba con rayas en la pared. El arriero contrataba a alguien que le ayudara a subir los enormes pellejos llenos y cargarlos en los carros que estaban forrados de esteras y entoldados. Los arrieros pagaban en efectivo al vendedor, a los ayudantes y al corredor, a éste un tanto por ciento de lo vendido y el precio de venta que dependía de la calidad y abundancia o escasez de la cosecha.

La operación se terminaba con una merienda en la que el arriero ponía la comida y el vendedor el vino. Éste, además, tenía que llenar la bota del arriero, que solía ser desmesurada (de hasta media cántara), para el camino. 
9. PlaGas de la VID

- Filoxera, insecto hemíptero que ataca las raíces de las plantas y las destruye. El único remedio consiste en la plantación de vides americanas, de las que ya hemos hablado.

- Mildeu, conocido como mildiu, mildeo y otras variantes más. Es un hongo que seca las hojas y racimos. Se combate con el sulfato.

- Oidio, otro hongo que se combate con azufre.

- El cuquillo, o cuquillo verde, mariposa que salía de la oruga que se comía las hojas tiernas. El cuquillo cagaba la calesa, huevecillos amarillos, en el envés de las hojas. Para combatirlo se desorugaban las cepas, esto es, se quitaban las hojas que tenían calesa. Hoy se combate con arseniato de plomo. Existía otro método, si no de combatirlo, sí al menos de protección: «bendecir el cuquillo». Este rito tenía lugar, y tiene, el día 9 de mayo, San Gregorio, y se desarrolla así: por la tarde de dicho día el Ayuntamiento en pleno acompaña al cura a bendecir los campos a lo alto de tres cuestas ${ }^{7}$ que rodean el pueblo adonde también acude en las rogativas anteriores a la Ascensión. A la vuelta, todos juntos celebran una merienda con un cordero que paga el Ayuntamiento.

- Gardama, insecto que destruía la yema de las cepas antes de deshojar. Se combate con arseniato de plomo. Según D.U.E. de María Moliner, es un sinónimo de carcoma, insecto coleóptero que destruye la madera.

\section{ARTURO MARTÍN CRIADO}

7 La palabra cuesta se emplea en Castrillo con el significado de cerro, y con él abunda en la toponimia. 
Se trata de una detallada descripción de los métodos tradicionales empleados en la plantación y el cultivo de la vid, así como del proceso de vinificación y los elementos técnicos y arquitectónicos que intervenían en él, según las encuestas realizadas en el pueblo de Castrillo de la Vega (Burgos). He prestado atención especial a los términos lingüísticos, cuyo estudio espero hacer en otra ocasión.

A detailed description of the process of planting and growing grapevine, including the gathering of grapes and the production of wine. All tools and structures used are discussed. The study is based on data obtained at Castrillo de la Vega, from peasants, rather advanced in age. A comparison with data provided in other villages of the same area shows very small differences, mostly concerning language, which I intend to discuss in a future study. 